\title{
LXV. The changes in velocity, in an electric field, of the $\alpha \beta$ and secondary rays from radioactive substances
}

\section{A.S. Eve M.A.}

To cite this article: A.S. Eve M.A. (1908) LXV. The changes in velocity, in an electric field, of the $\alpha \beta$ and secondary rays from radioactive substances, Philosophical Magazine Series 6, 15:90, 720-737, DOI: 10.1080/14786440809463812

To link to this article: http://dx.doi.org/10.1080/14786440809463812

曲 Published online: 16 Apr 2009.

Submit your article to this journal

Џll Article views: 2

View related articles ¿

Citing articles: 1 View citing articles ๔ 
The conditions being as in cases I., II., and V.,

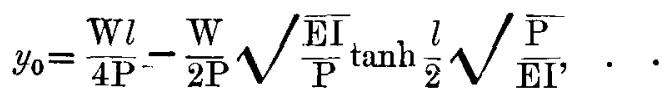

and the central bending moment

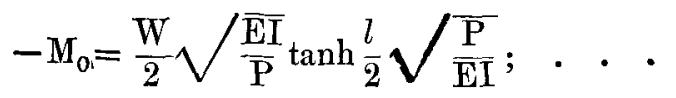

and expanding this

$$
\begin{aligned}
& -\mathrm{M}_{0}=\frac{\mathrm{W} l}{4}\left\{1-\frac{\pi^{2}}{12}\left(\frac{\mathrm{P}}{\mathrm{P}_{e}}\right)+\frac{\pi^{4}}{120}\left(\frac{\mathrm{P}}{\mathrm{P}_{e}}\right)^{2}-\frac{17 \pi^{6}}{20160}\left(\frac{\mathrm{P}}{\mathrm{P}_{e}}\right)^{3}+\ldots \& c .\right\}, \\
& \text { where } \mathrm{P}_{e}=\frac{\pi^{2} \mathrm{EI}}{l^{2}}
\end{aligned}
$$

or

$-\mathrm{M}_{0}=\frac{\mathrm{W} l}{4}-\frac{\mathrm{W} l^{3}}{48 \mathrm{EI}} \mathrm{P}\left\{1-\frac{\pi^{2}}{10}\left(\frac{\mathrm{P}}{\mathrm{P}_{e}}\right)+\frac{17 \pi^{4}}{1680}\left(\frac{\mathrm{P}}{\mathrm{P}_{e}}\right)^{2}-\ldots \& c_{.}\right\}$.

Here as in case V. for calculation of bending stresses method (b) is evidently a good approximation only when $\frac{\mathrm{P}}{\mathrm{P}_{e}}$ is small, $i$. e. when the bar is short or the lateral load great: for $\frac{\mathrm{P}}{\mathrm{P}_{a}}=\frac{1}{5}$ the error is 3 per cent.

Other cases with the same simple loadings as the above naturally suggest themselves, such for instance as those in which clamps fixing the ends at any assigned inclination to the axis of $x$ increase or decrease the flexure due to the lateral and axial loads, and those in which the longitudinal loads not passing through the centres of area of the ends of the strut or tie-rod may increase or decrease by their eccentricity the deflexion and bending moment resulting from the lateral loads.

LXV. The Changes in Velocity, in an Electric Field, of the $\alpha, \beta$ and Secondary Rays from Radioactive Substances. By A. S. Eve, M.A., Assistant Professor of Mathematics, and Lecturer in Radioactivity, Mc Gill University, Montreal* *

TN a paper on Secondary Radiation communicated to this 1 Magazine in December 1904, it was stated by me that the secondary rays from substances, due to the $\beta$ and $\gamma$ rays of radium, were homogeneous in character, and on that

* Communicated by the Author. 
supposition values of the coefficients of absorption by aluminium were given for various radiators. It has since been shown by S. J. Allen*, and others, that the secondary electrons really move with velocities as widely different as those of the $\beta$ rays themselves. The mistake in my paper arose partly from working with too thick an aluminium face to the electroscope, and from using too light a substance, namely paper, as radiator. Allen also proved that the secondary radiations from lead or zinc had penetrating powers and, therefore, velocities almost as great as those of the particles from radium $\mathrm{C}$; but that is not the case for light substances such as wood, paper, aluminium or paraffin.

It seems desirable in the first place to give corrected values $\dagger$ for the coefficients of absorption by aluminium in the case of some different secondary radiating substances, because these results have considerable bearing on the subsequent and main work deseribed in this communication.

The values of $\lambda$ for secondary rays have been determined in the following manner:-

About fourteen milligrams of pure radium bromide were placed in two sealed glass test-tubes. The primary $\beta$ and $\gamma$ rays struck the radiating plates, which were several centimetres thick, and had an area of $22 \times 22$ square centimetres. The secondary incident rays were tested in a gold-leaf electroscope of small natural leak, measuring $10 \times 10 \times 16$ c.c. One of the larger faces was removed, a few fine wires were stretched across, and the open side was then covered with thin aluminium leaf $0.00031 \mathrm{~cm}$. thick. Rutherford has found that passage through such a sheet of aluminium reduces the length of the range in air of the a particle by $0.5 \mathrm{~cm}$. oniy. It is certain, therefore, that such a layer of aluminium will scarcely affect the passage of $\beta$ or of secondary rays. In front of the electroscope aluminium screens could be placed; both these and the electroscope were separated from the radium by $15 \mathrm{cms}$. thickness of lead. The coefficients of absorption were caleulated in the ordinary way between the various thicknesses stated in the first column of Table I. In the first and second rows of figures the atomic weights and secondary radiation values are stated. In the second column are the values of $\lambda$ for primary rays, and in the other columns the values for secondary rays from the various substances named.

* Phys. Review, August 1906.

+ Since this paper was forwarded for publication I have read a communication by H. Starke in Le Radium (Feb. 1908). He had obtained results with which those given in the first part of this paper are in general agreement. 
TABLE I.

Values of $\lambda$ for aluminium as absorber. $\beta$ and $\gamma$ rays.

\begin{tabular}{|c|c|c|c|c|c|}
\hline & Primary. & \multicolumn{4}{|c|}{ SEcondary. } \\
\cline { 2 - 6 } Substance ..... & $\ldots$ & Lead. & Iron. & Brick. & Carbon. \\
\cline { 2 - 5 } Atomic Weight & $\ldots$ & 207 & 56 & $\ldots$ & 12 \\
Secondary & $\ldots$ & & & & \\
Radiation $\}. .$. & $\ldots$ & 106 & 72 & 48 & 36 \\
\hline Thickness & & & & & \\
in cms. A1. & & & & & \\
$0-009$ & 48 & 48 & 71 & 70 & 90 \\
$0-.021$ & 24 & 29 & 40 & 47 & 50 \\
$.021-\cdot 042$ & 19 & 20 & 31 & 23 & 28 \\
$.042-\cdot 063$ & 14 & 16 & 20 & 18 & 16 \\
$.063-\cdot 084$ & 12 & 14 & & 15 & 10 \\
$.084-\cdot 105$ & 10 & 12 & & 14 & \\
\hline
\end{tabular}

These figures show that the secondary rays from lead are nearly similar to the primary rays from radium, as Allen proved. The rays from the lighter substances are more easily absorbed, especially at first. The lighter the substance, the less is the radiation, the less is the grcup velocity, and the quicker the absorption by the screens.

It will be proved later by an electrical method that this is a case not of selective absorption, but of difference in velocity. The table shows also that the more penetrating rays from the various substances approximate in character to one another and to the primary rays. As the lighter substances emit electrons which, regarded as a group, have lower velocities than those from the heavier substances, we must conclude that the secondary rays are to a large extent intrinsic and projected from the radiating substance; they are not merely diffusely scattered primary rays. It may be remarked, however, that Allen has shown that the tertiary rays, from lead-lead-radium, are more easily absorbed than the secondary rays from lead. It is not difficult to arrange lead plates in such a way as to observe tertiary and even quaternary radiations. The relative amounts observed by me in one arrangement of apparatus were-

Secondary $\ldots \ldots 70 \cdot 5$ divisions a minute,

Tertiary ........ $6.7 \quad " \quad$ "

Quaternary ... $0.5 \quad, \quad$ " 
The values of $\lambda$ are more difficult to determine, but using an aluminium screen $0.021 \mathrm{~cm}$. thick, the values were about-

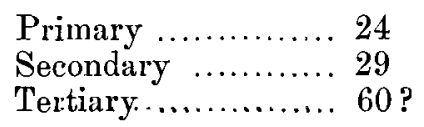

It is strange that whilst secondary rays from lead are so like the primary rays which cause them, yet the tertiary should be different in absorbability from both. Judging from the curves published by Allen, the tertiary rays from lead are absorbed at the same rate as the secondary rays from paper, and my results seem to agree; for the tertiary from lead and the secondary from carbon have values for $\lambda$ not far apart.

\section{Penetrating Secondary Rays.}

If lead and brick are respectively examined as radiators, and their radiations are in turn cut off from the electroscope by a thick book, or by a sufficient thickness of aluminium, it will then be found that brick becomes a more efficient radiator than lead. If curves are plotted with the thickness of screens as abscissæ and the ionizations in the electroscope as ordinates, then the curves cross one another The ionization values obtained in one experiment were :-

TABLE II.

\begin{tabular}{|c|c|c|}
\hline $\begin{array}{c}\text { Thickness of Aluminium } \\
\text { Screens. }\end{array}$ & Lead. & Brick. \\
\hline cm. & & \\
0 & 106 & 48 \\
04 & 37 & 15 \\
$\cdot 08$ & 20 & 10 \\
$\cdot 16$ & $8 \cdot 3$ & $7 \cdot 9$ \\
$\cdot 25$ & $5 \cdot 7$ & $7 \cdot 7$ \\
.50 & $4 \cdot 3$ & $6 \cdot 9$ \\
\hline
\end{tabular}

The lead and brick radiators were both a little more than 5 cms. thick, and of nearly the same area. Again, using two stout books as screens (Drude's 'Optics' and Wood's 'Optics'), protected in all cases from the radium by $15 \mathrm{cms}$. of lead, the figures obtained were-

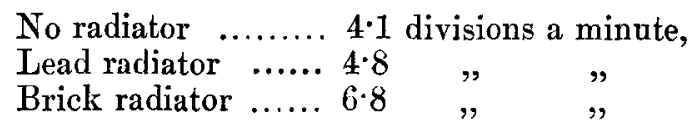


Using another book as screen the values for the radiators named, for a different arrangement from the above, were-

\begin{tabular}{lll} 
Radiator. & \multicolumn{2}{c}{ Ionization. } \\
None & $\ldots \ldots \ldots \ldots \ldots \ldots \ldots \ldots$ & $3 \cdot 00$ \\
Lead & $\ldots \ldots \ldots \ldots \ldots \ldots \ldots$. & $3 \cdot 44$ \\
Books & $\ldots \ldots \ldots \ldots \ldots \ldots \ldots$ & $4 \cdot 15$ \\
Carbon & $\ldots \ldots \ldots \ldots \ldots \ldots \ldots$ & $4 \cdot 50$ \\
Iron & $\ldots \ldots \ldots \ldots \ldots \ldots \ldots$ & $4 \cdot 60$ \\
Cement $\ldots \ldots \ldots \ldots \ldots \ldots \ldots$ & $4 \cdot 80$ \\
Brick & $\ldots \ldots \ldots \ldots \ldots \ldots \ldots$ & $5 \cdot 00$
\end{tabular}

These results agree with the statement made in my first paper, that thick blocks of brick, slate, cement, granite, give rise to very penetrating rays. It can be proved that these rays come from considerable depths. With a book screen and carbon radiators the effects in divisions a minute were-

Carbon.

No. of Radiating Plates. Secondary Radiation.

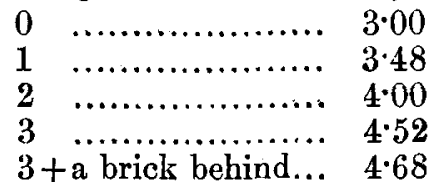

Now these carbon plates were each $1.5 \mathrm{~cm}$. thick.

Again, with wood or slate radiators, 0.75 and $0.5 \mathrm{~cm}$. thick respectively, the measured movements of the gold-leaf were, when the screen was 4 sheets of aluminium each 0.04 cm. thick, as follows :-

\begin{tabular}{|c|c|c|}
\hline \multirow[b]{2}{*}{ No. of Sheets of :- } & \multicolumn{2}{|c|}{ Radiators. } \\
\hline & Wood (each $075 \mathrm{~cm}$.$) .$ & Slate (each $0.5 \mathrm{~cm}$ ). \\
\hline $1, \ldots \ldots \ldots \ldots$ & $6 \cdot 42$ & 6.96 \\
\hline $2 \ldots \ldots \ldots \ldots$ & $6 \cdot 48$ & $7 \cdot 68$ \\
\hline ( $\ldots \ldots \ldots \ldots \ldots$ & $6 \cdot 50$ & $8 \cdot 37$ \\
\hline $4 \ldots \ldots \ldots \ldots \ldots$ & $\cdots$ & 8.91 \\
\hline $5 \ldots \ldots \ldots \ldots$ & 6.70 & - \\
\hline $6 \ldots \ldots \ldots \ldots$ & $\cdots$ & $9 \cdot 42$ \\
\hline $7 \ldots \ldots \ldots$ & 6.85 & - \\
\hline $8 \ldots \ldots \ldots \ldots$ & $\ldots$ & $9 \cdot 80$ \\
\hline $9 \ldots \ldots \ldots \ldots$ & $6 \cdot 97$ & - \\
\hline
\end{tabular}


Thus these penetrating rays came from a depth of about $6 \mathrm{cms}$. of wood or $4 \mathrm{cms}$. of slate. It is difficult to decide whether these rays are high velocity scattered primary $\beta$ rays, or secondary negative rays, or secondary $\gamma$ rays due to the primary $\gamma$ rays, or secondary $\gamma$ rays due to the expulsion of secondary $\beta$ rays, or secondary $\gamma$ rays due to the stopping of primary $\beta$ rays. There is some evidence that they are secondary $\gamma$ rays, but it is not conclusive. The paper by A. S. Mackenzie, in this Magazine, July 1907, shows that there are remarkable conditions, depending on direction, when $\gamma$ rays traverse matter.

In the experiments made by Cooke on the penetrating radiation due to the earth, he found that brick gave rise to a very penetrating radiation. As clay generally contains radium it was natural to attribute the effect observed by Cooke to the presence of radium in the brick. It is probable, however, that the penetrating rays were due to the secondary radiation set up in the bricks by the radium and thorium in the ground, and not chiefly by the minute amount in the bricks employed. I have not succeeded in obtaining these penetrating rays from lead; they appear to arise in the lighter substances.

\section{Electrical Method.}

By an important experiment it was proved by Lenard* that the cathode rays could be accelerated or retarded in an electric field, when the particles moved along the lines of force. He found that the value of $e / m$ remained nearly constant, whilst the change in the velocity amounted to more than 20 per cent. for a difference of potential of 29,000 volts.

It seemed possible to apply a similar method to the $\alpha$ and $\beta$ rays from the radioactive substances, and to the secondary rays produced by the $\beta$ and $\gamma$ rays.

$$
\text { a Rays. }
$$

A metal plate, $10 \times 8 \mathrm{cms}$., was charged negatively and exposed to the emanation from thorium hydroxide until an active deposit of maximum activity was obtained. The plate was then placed parallel and opposite to the thin aluminium face of the gold-leaf electroscope, and was insulated on a block of paraffin so that it could be charged to about 30,000 volts, either positive or negative, by a Wimshurst influence-machine. One pole of the machine was earthed, a Leyden-jar was used to steady the potential of the other, and the potential, which

* Lenard, Wied. Ann. xlv. (1898).

Phil. Mag. S. 6. Vol. 15. No. 90. June 1908. 3 C 
could be modified by a spark-gap, was measured by a Kelvin electrostatic voltmeter.

Fig. 1.

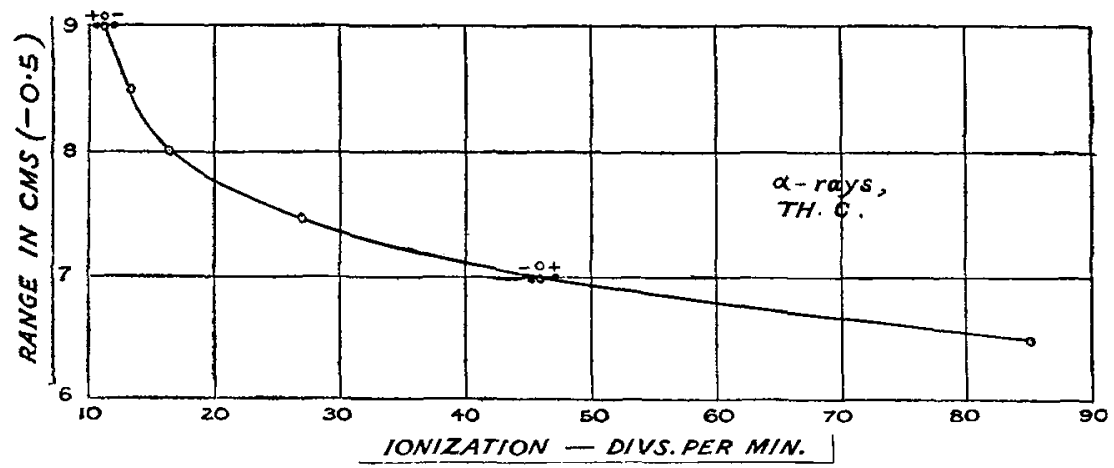

The range of the $\alpha$ particle from $\mathrm{Th} \mathrm{C}$ was found to be 8.5 cms. by Rutherford and Hahn; and the bend at $8 \mathrm{cms}$, shown in (fig. 1) is due to the entry of the $\alpha$ rays into the electroscope at that range, for it is known that the aluminium face of the electroscope is equivalent to $0.5 \mathrm{~cm}$. of air. The curve (fig. 1) is drawn with the ionization effects as abscissa and the ranges as ordinates, following the wellknown method of Bragg.

At $9 \mathrm{~cm}$. no a rays enter the electroscope, and a negative charge given to the active plate accelerates the $\beta$ rays, and a positive charge retards them. Oblique rays are bent towards or from the electroscope according to the sign of the charge. The charge actually ohserved was 12 per cent. of the mean value, and the effect for negative was greater than the effect for the positive charge.

At $7 \mathrm{cms}$. the $a$ rays were accelerated by a positive charge and retarded by a negative charge. The difference observed was 3 to $3 \cdot 5$ per cent. for potential-differences of $\pm 30,000$ volts, and the effect for a positive charge was then greater. At 8 cms. no change could be observed because the acceleration of the $\alpha$ rays balanced the retardation of the $\beta$ rays, and conversely. Only the very ends of the ranges of the $\alpha$ rays were inside the electroscope at this distance.

If the field were uniform the $\alpha$ particles, projected in all directions, would describe parabolas, bent towards the electroscope for a positive charge, and away from the electroscope for a negative charge. For the $\beta$ particles the reverse statement is true. The effect may be compared to the motion of 
water issuing from a rose at the end of a hose directed to or from the earth.

It is easy to estimate the change of velocity for an $\propto$ particle moving by any path from the plate at 30,000 volts to the electroscope at zero potential, for the change of kinetic energy is equal to the work done, so that

$$
\begin{gathered}
\frac{1}{2} m v^{2}-\frac{1}{2} m u^{2}= \pm e \mathrm{~V}, \\
\text { or } \quad v^{2}=u^{2} \pm 2 \frac{e}{n} \mathrm{~V} .
\end{gathered}
$$

Here $u$ is the velocity of projection, $v$ of arrival, $\mathrm{V}$ is the potential-difference, $e$ the ionic charge, and $m$ the mass, expressed in E.M. units, and grams. The sign selected depends upon that of the charge. It has been proved by Rutherford and Habn that for Th C,

$$
u=1.98 \times 1 y^{9}, \frac{e}{n \iota}=5 \cdot 6 \times 10^{3} \text {, and } \mathrm{V}=3 \times 10^{12} \text {. }
$$

\section{Hence}

$$
v^{2}=(393 \pm 3 \cdot 36) 10^{16} \text { and } v=19 \cdot 91 \times 10^{8} \text {, or } 19 \cdot 74 \times 10^{8} \text {; }
$$

so that the total calculated difference per cent. for a change of sign of the potential is 0.8 .

The effect of absorption by the air has not been considered. The change in ionization observed is not necessarily proportional to the change of velocity produced. The large change observed at $7 \mathrm{cms}$. ( 3 per cent.) was due in part to the bending of the rays, and to the consequent increased length of path, of the oblique rays, which is in the electroscope. Moreover, oblique rays which barely reach the electroscope when the plate is uncharged would be bent inside when the charge is given. The fact that no effect was observed at $8 \mathrm{cms}$. for a reversal of potential shows that the $\alpha$ ray change then balanced the $\beta$ ray change, and that the electric field altered the velocity of the normal $\alpha$ rays, and that the actual range of the $\alpha$ particles was increased or decreased according to the direction of the lines of force. I have endeavoured, hitherto without success, to observe this change of range with a Crookes spinthariscope, using an ebonite cylinder ; the eyepiece was earthed, and a wire, covered with radium $C$, was placed inside at the bottom on a plate raised to $\pm 30,000$ volts. It is easy to show that the expected change of range must be small and difficult to detect, about $1.4 \mathrm{~mm}$. for a reversal of potential *.

* Rutherford, Phil. Mag. Oct. 1906.

$3 \mathrm{C} 2$ 
A Kelvin dynamo-static machine, kindly lent by Professor Owens, enabled me to work at a higher potential than with the Wimshurst machine. But sparks passed from the Th C plate and perforated the thin face of the electroscope, and ions then rushed inside. The holes could be repaired with very thin aluminium leaf, but observations were difficult to make.

It may be here stated that it is important to have the mica windows of the electroscope as small as possible, otherwise the readings of the gold-leaf are not the same for positive and negative charges of the leaf, owing to induction effect, electric wind, \&c. It is well to have a large well-earthed sheet of wide-meshed wire-netting just in front of the electroscope. This screens off the induction effect, and it does not interfere with the success of the experiment. The motion of the gold-leaf was remarkably steady and unaffected by the high potential in its neighbourhood.

This experiment with the $\alpha$ rays shows in a simple manner the fact, proved by Rutherford, and later by Becquerel, that the a particle carries a positive charge, and it indicates that the length of the range of these particles can be increased or decreased to a slight extent by an electric field with lines of force in the direction of motion.

\section{$\beta$ Rays.}

Active matter containing radium, spread over a brass plate $10 \mathrm{cms}$. in diameter, was covered by just sufficient aluminium to absorb the $\alpha$ rays, and to prevent the escape of emanation. This, made by Dr. Rümelin, serves as a convenient $\beta$-ray standard. The plate was placed in front of the electroscope, about 20 cms. from it, and it was charged to $\pm 30,000$ volts. The total change in the ionization amounted to about 12 per cent. of the value when the plate was uncharged. A considerable part of this change is due to the bending of oblique rays, in or out of the electroscope according to the sign of the charge ; secondary rays from brass must be present. Using the dynamo-static machine and obtaining a higher voltage, about $\pm 50,000$, a difference of more than 15 per cent. was produced by a reversal of the electric field. As the potential is gradually increased from zero, the ionizations for positive and negative charges on the brass plate are not equidistant from the mean value (fig. 2). It appeared easier to retard and decrease the rays entering the electroscope than to accelerate and increase them. It is unfortunate that there is so little evidence as to the relationship between the magnitude of the velocity of electrons and the ionization produced by 
Electric Field of the $\alpha, \beta$, and Secondary Rays.

them. According to Townsend the ionization decreases as the velocity increases. Again, in the case of high velocity

Fig. 2.

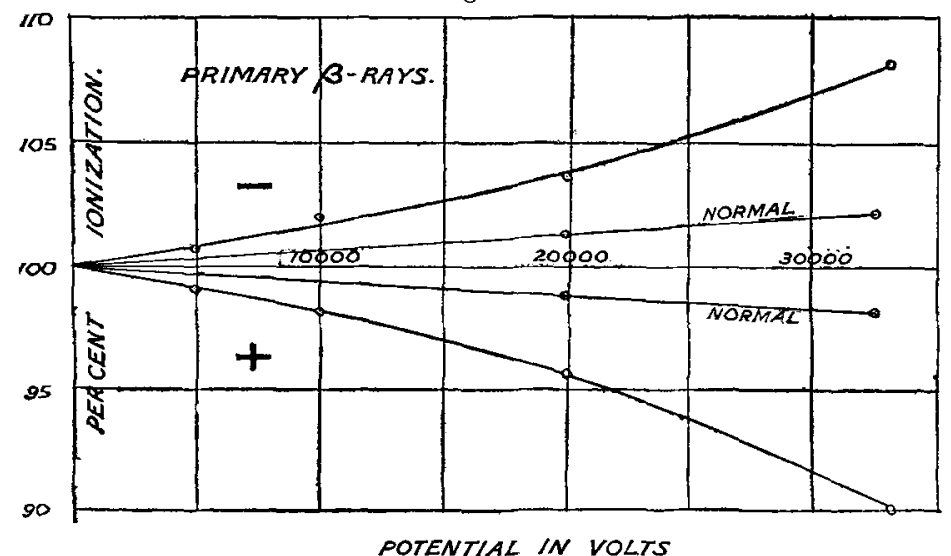

electrons it is difficult to increase their speeds because, as Kaufmann and others have shown, there is an increase of mass as the velocity approaches that of light. There are then two reasons why the outer curves, shown in fig. 2, should not be symmetrical about the axis of $x$.

It is easy to calculate the velocity of the $\beta$ particle on its arrival at the electroscope. As before, we write

$$
v^{2}=u^{2} \pm 2 \frac{e}{m} \mathrm{~V}
$$

But here we may take

Hence,

$$
\frac{e}{m}=10^{7} \text { and } u=2 \cdot 6 \times 10^{10} \text {. }
$$

so that

$$
u^{2}=6.7 \times 10^{20} \text { and } 2 \frac{e}{m} \mathrm{~V}=6 \times 10^{19} \text {, }
$$

and

$$
\begin{aligned}
v^{2} & =(67 \pm 6) 10^{19} \\
& =6 \cdot 1, \text { or } 7 \cdot 3, \times 10^{20}, \\
v & =2 \cdot 46, \text { or } 2 \cdot 70, \times 10^{10} .
\end{aligned}
$$

There is then a calculated difference equal to $9 \cdot 2$ per cent. of the mean value. But the difference produced in the velocity need not cause a proportional difference of ionization in the electroscope. The result calculated above is independent of the path of the electron. But if the number of electrons entering the electroscope varies for positive and 
negative charges on the active plate, then the observed effect will not correspond with that calculated.

In order to test this point experimentally, a capsule containing $1.5 \mathrm{mgs}$. of radium was placed so that the $\beta$ rays passed through a small hole in a block of wood, and entered normally the centre of the face of the electroscope. The diameter of the hole was $1.5 \mathrm{~cm}$, and the length of it was $10 \mathrm{cms}$. The block of wood was covered with thin aluminium foil, was insulated on a block of paraffin, and charged as previously described. The observed difference for positive and negative potentials was 6.3 per cent., or about two-thirds of the calculated value (inner curves, fig. 2). It must be borne in mind that the $\beta$ rays of radium always include secondary rays, and that a group of $\beta$ rays has a very wide range of velocity, from almost that of light to that of the slowest electrons produced by secondary, tertiary, or higher order radiation. The value for the velocity of projection of the $\beta$ particles assumed in the above calculation was selected from Allen's paper*, as being that derived under conditions most similar to those obtaining in my work.

In this case, as with the $\alpha$ particle, no allowance has been made for the absorption and scattering by air between the plate and the electroscope. Under more rigorous experimental conditions, it is possible that this method might throw light on the ionizations produced for various velocities of the electrons.

\section{Secondary Rays.}

The method described in this paper was next applied to the investigation of the nature of the secondary rays from various substances due to the $\beta$ and $\gamma$ rays from radium. About $14 \mathrm{mgs}$. of pure radium bromide were sealed in two thin glass test-tubes. The radiators were $5 \mathrm{cms}$. thick and measured $22 \times 22 \mathrm{cms}$. (fig. 3). They were insulated on blocks of paraffin and charged by the Wimshurst machine. A line from the radium to the centre of the radiating plate made an angle of $60^{\circ}$ with the normal. When the radiator is charged to a high potential the primary rays will be repelled from, or attracted to, the radiator to an extent depending on the sign and the magnitude of the potential. This variation of the primary rays might have been avoided by using $\gamma$ rays only; but $\gamma$ rays are always accompanied by secondary rays from the screen which cuts off the $\beta$ rays. Moreover, if all the radiators are of the same size and shape, and if they are placed in turn in the very same position, then, for any given

* Phys. Review, Aug. 1906. 
potential of whichever sign, the amount of primary $\beta$ and $\gamma$ rays falling on the plates will also be the same for all

Fig. 3.

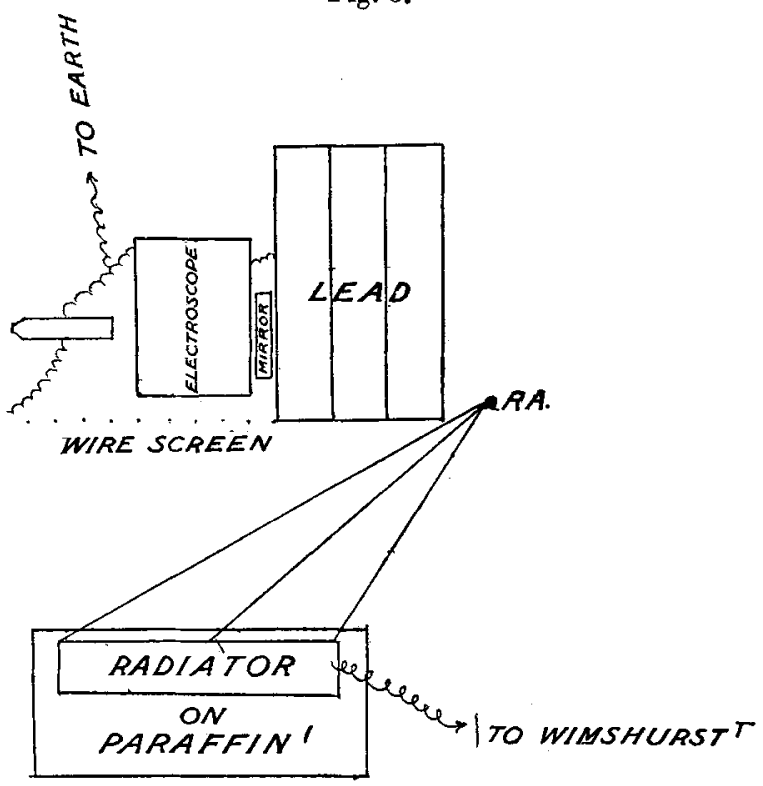

substances used as radiators. Thus we have a thoroughly satisfactory comparative test of the secondary radiations from the various materials employed.

The results obtained are shown in fig. 4 (p. 732), and it will be seen that the curves for each substance are unexpectedly symmetrical *. The abscissæ denote potentials and the ordinates the percentage ionization effects observed. The upper curves were obtained when the radiators were negatively charged, and the lower curves for the reverse charge.

It will be noted that the lighter substances emit rays which, regarded as a group, have a relatively low velocity. These slow electrons are readily retarded and made to diverge when the radiator has a positive charge, and easily accelerated and concentrnted by a repulsion towards the electroscope. The numerical values are given in Table III., p. 732 .

* The details of these curves (fig. 4) would repay further investigation. They diverge near the origin somewhat more rapidly than is shown in the figure, and there are some indications of points of inflexion on the upper curves. The details will necessarily depend on the angles and distances between the principal parts of the apparatus. 
732 Prof. A. S. Eve on Changes in Velocity in an

Fig. 4.

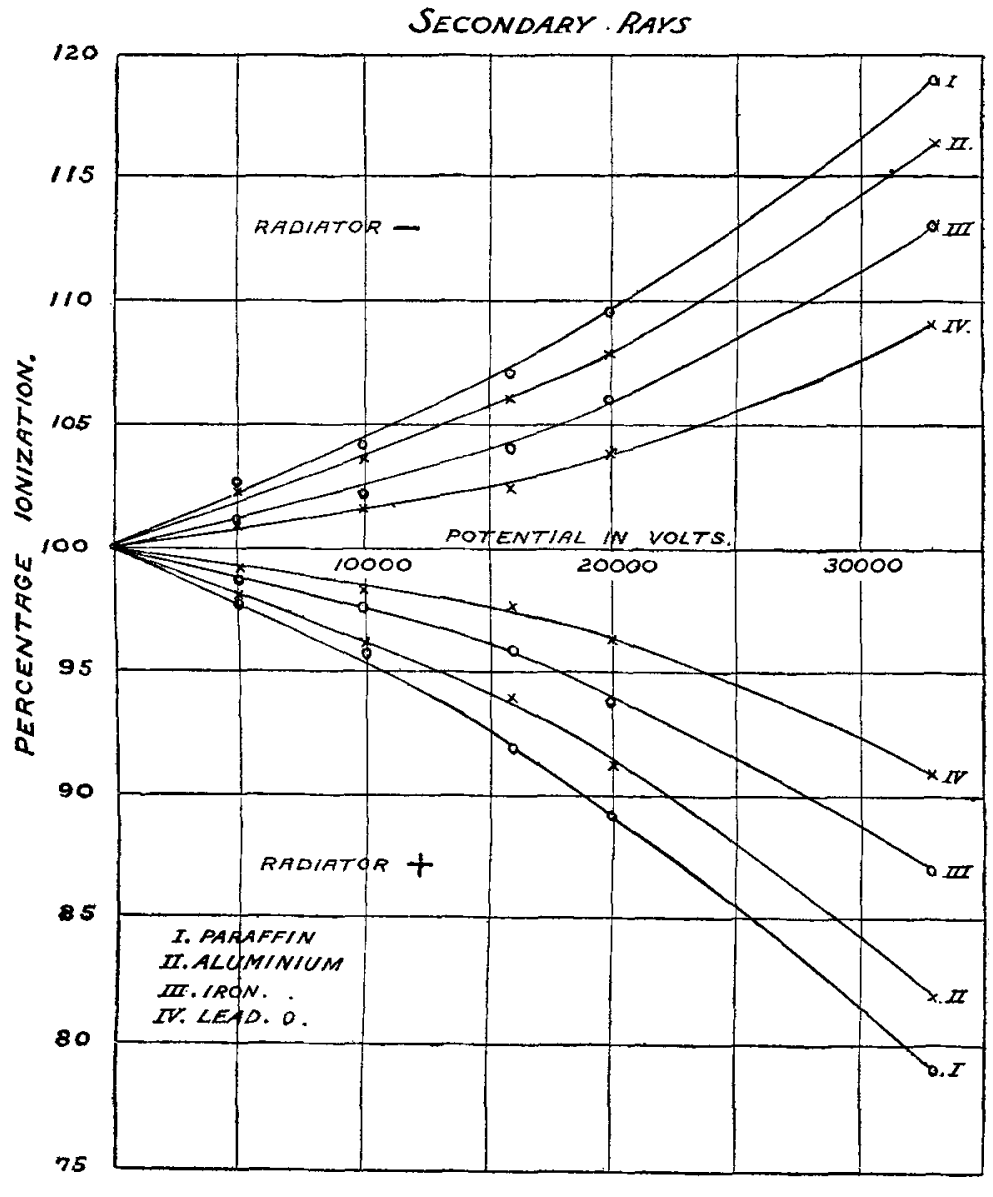

TABLE III.

\begin{tabular}{|c|c|c|c|c|c|}
\hline \multirow{2}{*}{ Substance. } & \multirow{2}{*}{ Density. } & \multirow{2}{*}{$\begin{array}{l}\text { Seeondary } \\
\text { Radiation. }\end{array}$} & \multicolumn{2}{|c|}{ Difference per cent. for } & \multirow{2}{*}{$\lambda$} \\
\hline & & & $\begin{array}{c} \pm 34,000 \\
\text { volts. }\end{array}$ & $\begin{array}{c} \pm 50,000 \\
\text { volts. }\end{array}$ & \\
\hline Lead ............. & $11 \cdot 4$ & 113 & 165 & 24 & $28 \cdot 3$ \\
\hline Iron.......... & $7 \cdot 8$ & 95 & $24 \cdot 6$ & 36 & $42 \cdot 0$ \\
\hline Aluminium ... & $2 \cdot 6$ & 80 & $35 \cdot 8$ & $\ldots$ & $\ldots$ \\
\hline Brick ............. & $2 \cdot 2$ & 79 & 340 & $\ldots$ & $50 \cdot 0$ \\
\hline Paraffin $\ldots . .$. & $0 \cdot 9$ & 65 & $41 \cdot 0$ & 48 & $\ldots$ \\
\hline
\end{tabular}


The third column gives the secondary radiation actually observed from the blocks used as radiators. The fourth column shows the differences per cent. on the mean value when the radiators were charged to 30,000 volts, first positive and then negative. In the fifth column are the differences per cent. for a higher potential, obtained with the dynamostatic machine. In the last column are the values of the coefficients of absorption by aluminium, $0.021 \mathrm{~cm}$. thick, requoted from the first part of this paper. In this experiment the bricks were slightly moistened to make them conductors, and the paraffin was covered with aluminium foil, $\cdot 00031 \mathrm{~cm}$. thick. This thin layer of aluminium did not affect the radiation to a measurable extent, and it made the surface a conductor.

By a comparison of the fourth and fifth columns it appears that it becomes increasingly difficult, as the potential rises, to magnify the percentage differences for opposite charges of the radiator. The values of the coefficients of absorption in Table I. are also in accord with the view that together with the slower electrons, which form the bulk of the radiation from the lighter substances, there are also swifter electrons, which are with greater difficulty absorbed by matter or affected by an electric field.

These experiments as a whole indicate that the secondary rays from various substances have a distinctive group velocity depending on the density or atomic weight of the substance of the radiator. The values of the secondary radiation follow the order of the atomic weight, as shown by McClelland: it is now seen that the values of $\lambda$ are also in inverse order of the secondary radiations, and that the percentage changes of ionization, due to the reversal of the electric field, are in that same inverse order.

Hence, secondary rays are in the main intrinsic, released from the atoms of the radiating substance, with distinctive group velocities depending on the density of the radiator. It appears that the secondary rays are for the most part not due to dispersed primary rays, which have entered the radiator, and by changes of path re-emerged; but it is not. improbable that the secondary rays may include an unknown fraction of such primary rays. Thus $\beta$ and $\gamma$ rays appear merely to release the electrons, which issue from the radiators with velocities possibly depending on those which they had in the radiator *.

* Since writing the above I have received a paper by Bragg and Madsen (Trans of R. Soe. of S. Australia, 2 Jan. 1908; Phil. Mag. May 1908) advocating a different view. 
If we take, for any radiating substance, the square root of the double ordinate, or percentage difference, at 20,000 or at 30,000 volts, and multiply by the actual secondary radiation from the plate, we get, with no great accuracy, a constant.

For example, with $\pm 34,000$ volts :-

\begin{tabular}{|c|c|c|c|c|}
\hline Substance. & $\begin{array}{c}\text { Percentage } \\
\text { Difference. }\end{array}$ & $\begin{array}{c}\text { Square } \\
\text { Root. }\end{array}$ & $\begin{array}{c}\text { Secondary } \\
\text { Radiation. }\end{array}$ & Product. \\
\hline Carbon .......... & $35 \cdot 6$ & $5 \cdot 96$ & 69 & 410 \\
Paraffin ......... & $41 \cdot 0$ & $6 \cdot 40$ & 65 & 415 \\
Brick ........... & $34 \cdot 0$ & $5 \cdot 84$ & 79 & 470 \\
Aluminium ... & 35.8 & 5.98 & 80 & 476 \\
Iron ........... & 24.6 & 4.96 & 95 & 470 \\
Lead ............ & 16.5 & 4.06 & 113 & 460 \\
\hline
\end{tabular}

This approximate rule emphasises the relationship between the velocity of the secondary rays and the amount of secondary radiation. The rule requires further investigation before it can be affirmed.

At some distance from the origin the curves shown on fig. 3 crudely resemble the parabola $x^{2}=k y$, where $k$ is a constant for each radiator. In the case of the less dense substances, it is found that when either the potential, or the distance between radiator and electroscope, is increased, there is not symmetry about the $x$ axis, but the positive ordinates are numerically less than the negative ordinates for the same abscissæ. With a sufficiently high positive voltage the ionization could be reduced to zero, and a very large negative potential would cause each curve to approach an asymptote parallel to the $x$ axis.

Some preliminary experiments were made to compare the quantity and quality of the secondary rays from hot iron plates and from hot bricks. The results were but slightly different, if at all, from those obtained from cold bricks and cold iron. Observations were made on radiators from a redheat to the temperature of the room.

It is usual to suppose that the secondary rays, which start from some depth within the radiator, must lose velocity on their passage through matter before they make their escape. The remarkable experiment of H. W. Schmidt * throws doubt 
on this view. The result obtained by him was not for a wide range of thickness, amounting only to $0.5 \mathrm{~mm}$. of aluminium, but within that limit he proved that the $\beta$ rays from radium E continued to move with undiminished speed until they were actually absorbed. There is no doubt that after passage through matter the swifter electrons emerge, because the slower are first of all absorbed. The question remains an open one, whether the $\beta$ particle loses velocity during its passage through a considerable thickness of matter. The question is always complicated by the attendant train of secondary rays which everywhere arise in the path of the particle through matter from the moment of its emission to the time of its complete absorption. In the case of the a particle, Rutherford has clearly proved that velocity is lost during passage through matter.

In conclusion, one more experiment may be described. Fourteen milligrams of radium bromide were enclosed in a cylindrical block so that the $\gamma$ rays passed through $2.5 \mathrm{cms}$. of lead before emerging to the air. The lead block was insulated, and placed before the electroscope. The potential was changed from + to $-30,000$ volts. The difference of the ionization observed was 3 per cent. of the mean value. The inner curves (fg. 2), otherwise obtained, almost represent the results of this experiment. The total ionization observed was mainly due to $\gamma$ rays, and the change of ionization, on reversal of the sign of potential, was due to the electrons, which are projected from the surface of matter traversed by the $\gamma$ rays*.

This paper must be considered as preliminary, and there are some criticisms which may be applied to the method and to the arrangement of apparatus. Thus it is difficult to estimate the effect of the scattering and absorption by air of the rays employed, but it is not relatively large. Again, it might be expected that some of the ions generated outside the electroscope near the active plate would be accelerated in the electric field sufficiently to enter the electroscope. This either did not take place, or the effect was relatively too small to be noticed.

It is hoped that these experiments may be extended to other substances and that higher potentials will be employed. The electric method may throw some light on the ratio of the amounts of secondary $X$ rays and of negative rays from 
radiators exposed to primary Röntgen rays*. The investigation of transmitted rays, and particularly of the rays from hot and cold bodies, should prove interesting when this method is applied.

Some of the work done overlaps that by Allen, with magnetic and electric deflexion methods. I trust that full justice has been done in making references to his valuable paper.

\section{Summary.}

1. The coefficients of absorption by aluminium of the incident secondary radiations, due to the $\beta$ and $\gamma$ rays of radium, produced from various substances have been determined. The lighter substances emit negative rays not only less in quantity than the dense, but these rays are initially more readily absorbed. (Allen.)

2. Some substances, such as brick, slate, wood, paper, and carbon, give rise to penetrating incident secondary rays originating from several centimetres deptb, which are either secondary $\gamma$ rays or high velocity negative rays. After screening, the secondary radiation from brick or paper may exceed that from a heavy substance, such as lead.

3. In an electric field, with the lines of force parallel to those of direction of motion, the velocity of the $\alpha$ rays can be increased or diminished, and there is apparently a slight variation of range.

4. The same method may be applied to primary $\beta$ rays or to secondary rays due to $\beta$ and $\gamma$ rays.

5. The amount of secondary radiation is known to follow an order depending on the atomic weights of the radiators. It is shown by the method herein described that the velocities, regarded as a group, as well as the initial absorptions by aluminium, follow the same order, so that the main secondary negative rays are projected with velocities, which are a function of the density, or the atomic weight, of the radiating substance, the velocities being greater for the more dense. The main group of electrons therefore emerge with less velocity from the lighter substances.

* Recent experiments have been made, using the electric method described in this paper, with the secondary rays due to (1) $X$ rays and (2) $\gamma$ rays. In the case of $X$ rays the cathode secondary rays are so rapidly absorbed by the air that they do not reach the electroscope. Hence a change from + to $-50,000$ volts in the potential of the secondary radiator made no difference in the jonization current. Perhaps there was a slight effect in the case of lead. The secondary rays, due to $\gamma$ rays, gave percentage changes about equal to those observed in the secondary rays due to both $\beta$ and $\gamma$ rays of radium. 
6 . The square root of the percentage differences of ionization, due to a reversal of potential of the radiator, is inversely proportional to the secondary radiation from the radiator. This is a rough approximation for radiators of equal areas made of different substances.

\section{McGill University, Montreal,} February 1908.

\section{Note added 25th April, 1908.}

In this paper I have upheld the old view that the secondary rays due to radium are not merely scattered primary. The experiments of H. W. Schmidt (Pliys. Zeit. June 1,1907 ) have to some extent weakened this theory. But the same observer has also shown that the $\beta$ particle does not lose speed in passing through matter; and, if that is the case, the secondary electrons should have the same velocity as the primary; and they have not. Again, $\gamma$ rays (we will suppose them to be wther pulses) give rise to secondary rays with velocities nearly equal to those of the secondary rays due to $\beta$ particles. There seems no reason to suppose that the $\beta$ rays could not cause the same projection of electrons from the atoms of the secondary radiator which we know that the $\gamma$ rays cause. It is true that the view, advocated by Bragg, of the material nature of the $\gamma$ rays is not out of harmony with observed facts; and, if that theory is correct, we may regard all secondary radiations, consisting of electrons with high velocities, as scattered primary rays.

\section{On the Electrical Charge of the Active Deposit of Actinium. By Sidney Ross, Demonstrator in Physics, Manchester University*.}

$\mathbf{E}$ XPERIMENTS by several observers have shown that the active deposit of Thorium is aimost entirely directed to a negative electrode.

If into a vessel containing thorium emanation two wires be inserted, one charged negatively, the other positively, the amount of active deposit obtained on the negative wire is more than one hundred times that on the positive; this number, however, shows a considerable reduction if the pressure in the vessel is diminished to a few millimetres.

* Communicated by Prof. E. Rutherford, F.R.S. 